\title{
Integration of Travel Agencies with other Supply Chain Members: Impact on Efficiency
}

\author{
Darja TOPOLŠEK', Dejan DRAGAN' \\ 1 University of Maribor/Faculty of Logistics, Celje, Slovenia
}

\begin{abstract}
The performance of tourism supply chains depends on the efficiency of all members involved, including the travel agencies. The paper addresses the analysis of relationships between the agencies' external integration with other supply chain members on one side, and the efficiency of the agencies on the other. The data envelopment analysis is applied for the estimation of efficiencies, while the structural equation modelling (SEM) is conducted for identification of possible integration impacts on the efficiency. Results show that integration with other supply chain members indeed has some positive impacts on the agencies' efficiency. Also, the developed SEM model implies that in-depth forms of collaboration would enable more effective exploitation of the identified relations between the integration and efficiency of the agencies. This finding could be an important guideline for the agencies' management in the sense of achieving more satisfied customers and bigger profits, as well as reduced operational costs.
\end{abstract}

Key words- Tourism industry, Tourism supply chains, External integration, Travel agencies' efficiency, Data envelopment analysis, Structural equation modelling.

\section{INTRODUCTION}

The tourism sector represents a significant part of the gross domestic product (GDP) in most countries worldwide. It is estimated that tourism contributed even $9.5 \%$ share of global GDP in 2013 , which will most likely continue to increase, probably even faster than shares of other industrial sectors such as transportation or manufacturing (Council, 2014).

In recent years, Europe is becoming one of the most important tourism destinations. As a consequence, the tourism industry has converted into a key sector of the European economy, creating more than $10 \%$ of the GDP of European Union, with employing 9.7 million citizens in 1.8 million companies (Group, 2012).

Conversely to other industries, the tourism industry is less attractive to scholars. However, in the last years, we can find some significant research studies in this field (Evans, 2003; Lafferty \& Fossen, 2001; Nunkoo \& Ramkissoon, 2012; Singh, 2008; Tapper, 2004; Yllmaz \& Bititci, 2006). These studies address many aspects of management of tourism supply chains (SC), from collaboration topics and problems, all over to performance measurement issues.

All members of tourism supply chain depend on each other and cooperatively contribute to overall performance and efficiency of the entire chain (Evans, 2003). Such cooperation can be developed in vertical or horizontal direction, and is considered as a certain sort of external integration (El) (YIlmaz \& Bititci, 2006).

In the manufacturing sector, many research works have been dedicated to the studying of relationships between the external integration of the SC members on one side, and their performance, as well as efficiency, on the other side (Flynn, Huo, \& Zhao, 2010; Frohlich \& Westbrook, 2001). A growing body of these studies has discovered that the increased degree of integration can contribute to improved performance and efficiency of SC members (Vickery, Jayaram, Droge, \& Calantone, 2003; Zhang, Song, \& Huang, 2009).

In contrast to the manufacturing sector, there have not been much research studies reported for service sectors, such as tourism sector, that would investigate the impact of external integration on firm's performance and efficiency. Probably the main reason is that for the tourism industry, it is quite difficult to assess and evaluate the effectiveness of companies (McLaughlin \& Coffey, 1990).

Even fewer such studies have been conducted for the travel agencies, which are prominent members of tourism supply chains. The agencies are selling holiday packages to its customers, as well as organizing transportation services (e.g. airplanes, trains, buses, cars), accommodations (e.g. 
hotels, motels, lodges, houses), trips (e.g. excursions, tours), and other related services (e.g. insurances, foreign currency exchange) (Singh, 2008).

The primary focus of this paper is to investigate the influence of external integration with other SC members on the agencies' efficiency. As other SC members, the following types of companies are included: accommodation and insurance companies, tour operators, and other (partner) travel agencies. It is supposed that, similarly as in manufacturing sector, the increased level of integration might lead to increased efficiency as well. To the best of our knowledge, there has been quite a few similar research (e.g. (Kovačić, Topolšek, \& Dragan, 2015; Topolšek, Kovačić, \& Cvahte, 2014; Topolšek, Mrnjavac, \& Kovačić, 2014)) reported in the scholarly literature. Thus, the conclusions of this research could serve as a primary contribution of this paper.

For the purpose of research, a survey among certain Croatian travel agencies located along the Adriatic Sea was conducted. The efficiency of the agencies was calculated by the means of data envelopment analysis (DEA) (Cooper, Seiford, \& Tone 2006). In the further analysis, exploratory and confirmatory factor analysis (EFA, CFA), and structural equation modelling (SEM) were applied (Byrne, 2009; Hair, 2010; Hoyle, 2012; Kline, 2005).

The derived structural equation model (SEM model) enabled us to examine the relationships between the measured items (observed indicators) and the un-measurable latent factors (constructs) of addressed external integrations (Els). Also, the causal relations between these factors and the single-item latent construct representing efficiency (EFF) were exposed. The calculations were executed in the program package IBM SPSS V21 and its extension AMOS.

\section{LITERATURE REVIEW}

\section{A. Tourism supply chains}

The tourism supply chains can be defined as a complex system of tourism organizations, which are involved in numerous activities related to the supply of tourism services/products, as well as a distribution of the latter to a certain tourism destination (Zhang et al., 2009). The main difference between this kind of supply chains and those of other sectors is that the tourists are travelling with a product of a particularly significant service component (Tapper, 2004). In tourism supply chains, a high proportion of personnel are involved, whose the main objective is to ensure the rapid production of the holiday experience.

The tourism supply chains rely on business relations between its members while the management can contribute considerably to performance improvements (Véronneau \& Roy, 2009; Zhang et al., 2009). Accordingly, the persistent improvement of business operations by each member in the supply chain is desired, and sustainability based collaboration is preferred (Lemmetyinen, 2010; Tapper, 2004).

Constant performance and efficiency improvements are also fundamental for the travel agencies, which are involved in booking, planning, and documenting of travel arrangements for its customers. Besides, their activities also include advertising, advising, and promoting their services (Singh, 2008).

\section{B. Integration in tourism supply chains}

The tourism supply chains comprise collaboration, coordination, and integration of complex heterogeneous mechanisms and activities (e.g. transportation, accommodations, and so on) in uncertain dynamic environments (Véronneau \& Roy, 2009). They are quite often challenged with the aggressive opposition and considerable variations in the demand, to whom must be well equipped (Zhang et al., 2009).

There have been numerous definitions of integration in the tourism supply chains introduced. For instance, if external integration is taken into consideration, it can be defined as a set of fluid business relationships between different supply chain members. Occasionally, the external integration is also addressed as some form of interaction, collaboration, and communication outside the borders of the main organization (Griffin \& Hauser, 1996; Rinehart, Bixby Cooper, \& Wagenheim, 1989; Stock, Greis, \& Kasarda, 2000). Similarly, some other researchers treat SC integration as a level of strategic collaboration of a particular supply chain member with its partners in the framework of interorganizational and intra-organizational processes management (Flynn et al., 2010). 
According to (Lee, 2000), the supply chain external integration encompasses three principal dimensions: information sharing, coordination and resource sharing, and organizational linkage. These dimensions include sharing of information about production plans, inventory status, sales forecasts, and promotion plans, as well as the realignment of decision making in the supply chain.

Most scholars agree that the integration strives to achieve such effective flows of services/products, decisions, information, and cash so that the top quality of services at the lowest possible costs and highest possible speed is brought to the customers (Flynn et al., 2010; Frohlich \& Westbrook, 2001). External integration also assists the companies to achieve competitive advantages over their opponents and facilitate their entry into the market (Lafferty \& Fossen, 2001). Moreover, it provides the means to reduce transaction costs, enables the market entry at lower prices, and supports priority access to top destinations (Bull, 1995; Thea Sinclair \& Stabler, 1997; Topolšek, Mrnjavac, et al., 2014).

\section{Integration based performance in tourism supply chains}

Several scholars have also reported that tourism supply chain integration leads to increased company performance of individual SC members, similarly as in manufacturing sector. However, these studies have mainly focused on two different fields. The first field is mostly limited to a particular sector, for instance, to the hotel sector (Atkinson \& Brander Brown, 2001; Enz, Canina, \& Walsh, 2001; Mia \& Patiar, 2001; Phillips, 1999).

Conversely, the studies of the second field investigate the relationships that typically arise between service providers (e.g. hotels and airlines) on one side, and mediators (e.g. tour operators) on the other (Bastakis, Buhalis, \& Butler, 2004; Theuvsen, 2004; Zhang et al., 2009). Bastakis and his colleagues (Bastakis et al., 2004) have identified bad personal and professional relations in mutual communication between hotels and tour operators. On the other side, Theuvsen (Theuvsen, 2004) has discovered that the principal European tour operators are extraordinarily vertically integrated with hotels, airlines, and other service providers, hence good collaboration can bring quite great benefits to all parties involved in the supply chain (Theuvsen, 2004; Zhang et al., 2009).

Above mentioned studies mostly agree that efficient integration and optimal coordination of business operations and activities lead to reduced operating costs, and improved firms' agility, flexibility, and competitiveness throughout the entire supply chain (Sigala, 2008; Zhang et al., 2009). Integration thus has numerous advantages, primarily reflected in increased firm performance and success.

Further literature from the field of tourism supply chain integration and performance can be considered in survey work (Dragan, 2015), where some important references regarding two-party relationships, integration, and cooperation, as well as performance measurement can be found.

\section{Efficiency in tourism supply chains}

Company's success and performance are often related to economic efficiency, which can be viewed from two aspects, technical and allocative efficiency (Heshmati, 2003). Efficiency in the tourism sector has been researched in different fields and for different supply chain members. For example, works (L. T. Liang, Yang, J. T. , 2012; Yi \& Liang, 2014) have provided a complete overview of tourism industry efficiency, while several scholars have also studied efficiency related to hotels (A. Assaf, Barros, \& Josiassen, 2010; A. G. Assaf \& Magnini, 2012; Manasakis, Apostolakis, \& Datseris, 2013; Shang, Wang, \& Hung, 2010). On the other side, some studies have investigated city and regional tourism based efficiency (M. Liang, Yi, T. , 2012; Suzuki, Nijkamp, \& Rietveld, 2011; Wang, 2013; Yan, 2013), while the other have also examined tour operators based efficiency (e.g. (A. G. Assaf, Barros, \& Dieke, 2011)1.

\section{E. Detected gaps for the case of travel agencies}

In the case of travel agencies, there is a quite big gap detected regarding the analysis of their efficiency and/or integration. Moreover, surprisingly, there are even fewer studies identified, which would try to investigate the agencies' efficiency in relation to their external integration. For instance, one such study is work of authors (Kovačić et al., 2015), where the relations between agencies' 
external integration with different transport providers on one hand, and efficiency of the agencies on the other hand, is studied with emphasis on various estimators' comparison.

Conversely, some other studies have only partly examined integration and/or performance issues for the agencies, as they were quite limited, without any additional targeted concerns about the efficiency. For example, some researchers have investigated the collaboration of the agencies with single transport suppliers, such as airlines (Alamdari, 2002), or with multiple transport providers (bus, rail, water, air) ((Topolšek, Kovačić, et al., 2014). Alamdari (Alamdari, 2002) has discovered that the higher level of integration between the travel agencies and airline companies also results in faster and more effective way of purchasing airline tickets. On the other side, Topolšek and her colleagues (Topolšek, Kovačić, et al., 2014) have mostly focused on causes that affect the level of collaboration between the travel agencies and different transport providers.

Some scholars have also examined relationships between travel agencies and wholesalers (e.g. (Tsaur, 2006)), while the other have carried out a similar type of research for relations between the agencies and hotels (e.g. (Medina-Muñoz \& García-Falcón, 2000)). Medina-Muñoz and GarcíaFalcón (Medina-Muñoz \& García-Falcón, 2000) have concluded that in order to establish good relations, communication between parties involved must be timely processed, accurate and performed in a credible manner.

Since our study investigates the agencies' efficiency related to the external integration with several other tourism supply chain members (accommodation and insurance companies, tour operators, other travel agencies), we believe that this might be one of the main contributions of this paper.

\section{CONCEPTUAL FRAMEWORK, HYPOTHESIS DEVELOPMENT, AND SURVEY}

\section{A. Conceptual framework and questionnaire}

For the purpose of research, a survey among selected Croatian travel agencies located along the Adriatic Sea was applied. For the assessing of behavioural magnitudes of agencies' external integration with other supply chain members, the following three crucial dimensions were used: consultation, interaction, and collaboration (Topolšek, Kovačić, et al., 2014). These measurement scales were based on some previously applied questionnaires (e.g. (Denise, 2007; Ellinger, 2000; Gimenez \& Ventura, 2005; Topolšek, Čižman, \& Lipičnik, 2010)) and then modified for our study.

The conceptual framework of hypothesized model is shown in Fig. 1. The conducted questionnaire was separated into two parts, the Els part, and the efficiency's part. The first part referred to the agencies' external integration with accommodation companies, insurance companies, and tour operators or other travel agencies. Here, the behavioural dimensions were assessed via 11 ordinal indicator items, as follows (see Table 1 and Fig. 1): $T_{i}=Q_{i 1}, i=1, \ldots, 11$ (for tour operators/other travel agencies), $A_{i}=Q_{i 2}, i=1, \ldots, 11$ (for accommodation companies), and $I_{i}=Q_{i 3}, i=1, \ldots, 11$ (for insurance companies). The exact meaning of questions denoted by $Q_{i j}, i=1, \ldots, 11, j=1,2,3$ can be seen in Fig. 1 and in table in Appendix 1 . The ordinal variables $T_{i}, A_{i}, I_{i}$ were formed by interviewing the leaders of travel agencies. They were asked to estimate a strength of the relationships with other supply chain members, for which an ordinal scale from 1 to 5 (1 - 'zero cooperation', ..., 5 - 'total cooperation') was employed.

The second part of the questionnaire contained five indicator variables (agencies' internal variables $x_{i}, i=1,2,3, y_{j}, j=1,2$ ), necessary to calculate the agencies' efficiencies (see Fig. 1 and Table 1 for the meaning of these variables). At this place, the leaders were asked to provide the data about two groups of variables: the three 'input' variables $\left(x_{i}, i=1,2,3\right)$, and the two 'output' variables $\left(y_{j}, j=1,2\right)$. These variables were later used in the DEA analysis, where the input-oriented model was applied to calculate the minimum possible inputs in order to achieve maximum outputs of the agencies (similarly as it was done in the study of Fuentes, 2011 (Fuentes, 2011)). 


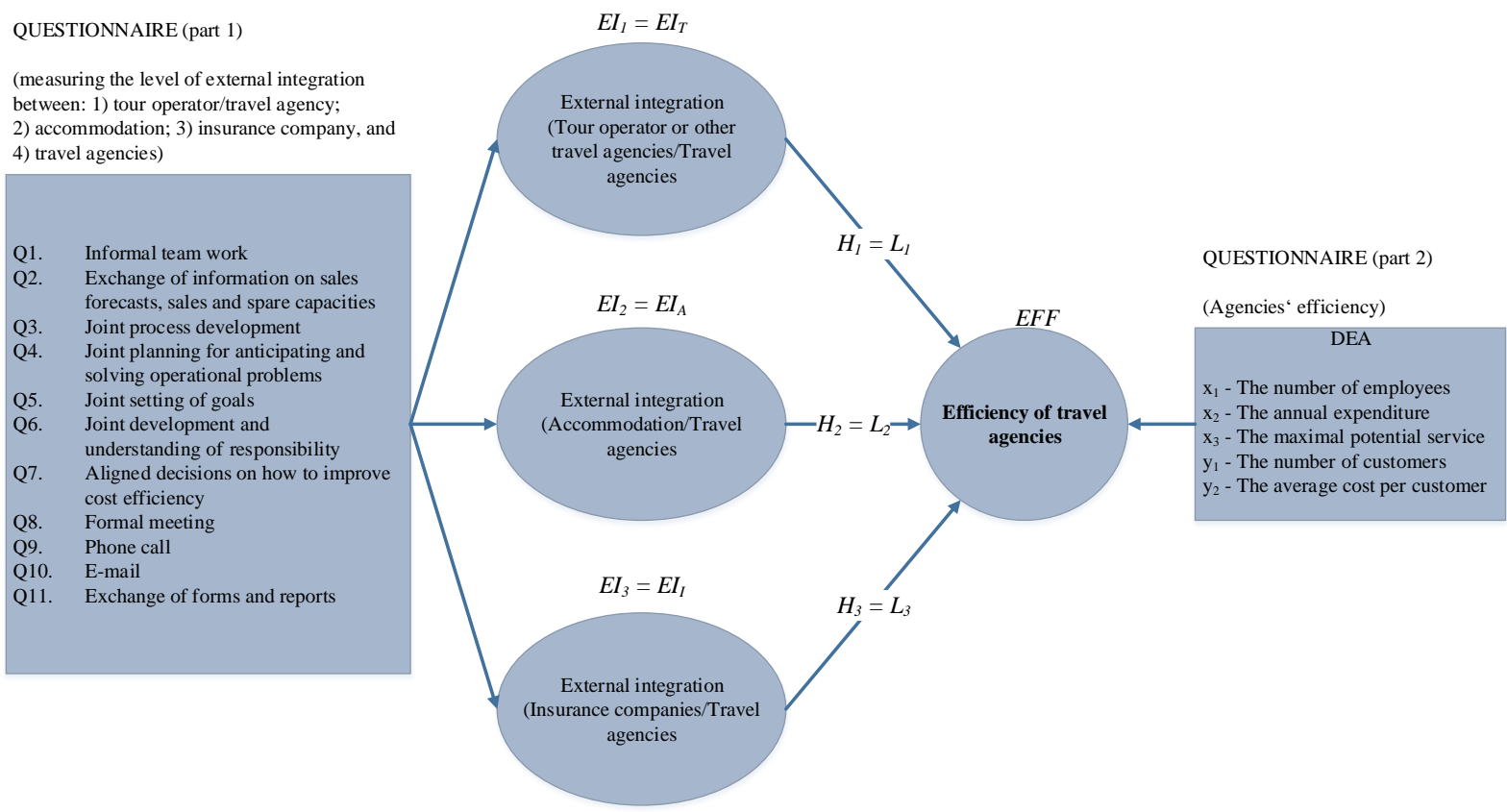

Figure 1. The conceptual framework.

Table 1. Applied variables of the questionnaire.

\begin{tabular}{lc}
\hline \multicolumn{1}{c}{ Questionnaire (first part) } \\
\hline \multicolumn{1}{c}{ Variables } & Notation \\
Items for El with tour operators/other travel agencies & $T_{i}=Q_{i 1}, i=1, \ldots, 11$ \\
Items for El with accommodation companies & $A_{i}=Q_{i 2}, i=1, \ldots, 11$ \\
Items for El with insurance companies & $I_{i}=Q_{i 3}, i=1, \ldots, 11$ \\
\hline \multicolumn{2}{c}{ Questionnaire (second part) } \\
\hline The number of employees & Notation \\
The annual expenditure & $\boldsymbol{x}_{\mathbf{1}}$ \\
The potential service, which the agency can provide & $\boldsymbol{x}_{\mathbf{2}}$ \\
The number of customers & $\boldsymbol{x}_{\mathbf{3}}$ \\
The average cost per customer & $\boldsymbol{y}_{\mathbf{1}}$ \\
$\boldsymbol{y}_{\mathbf{2}}$
\end{tabular}

\section{B. Hypothesis development}

As it can be seen in Fig. 1 and Table 2, we have conducted three main hypotheses $H_{i}, i=1,2,3$ suggesting that there exists certain impact of integrations $E I_{i}, i=1,2,3$ on the efficiency (EFF) of the agencies. By setting such causal relations between these unmeasurable constructs, we presumed that behavioral dimensions of agencies' external integration with other supply chain members might positively affect their efficiency. 
Table 2. Presumed hypotheses.

\begin{tabular}{cl}
\hline $\begin{array}{c}\text { Notation of } \\
\text { Hypothesis }\end{array}$ & \multicolumn{1}{c}{ The Content of hypothesis } \\
\hline$H_{1}:$ & $\begin{array}{l}\text { El between the tour operators/other travel agencies and the travel agencies } \\
\left.E I_{1}\right) \text { has a positive impact on the travel agencies' efficiency EFF. }\end{array}$ \\
$H_{2}:$ & $\begin{array}{l}\text { El between the accommodation companies and the travel agencies }\left(E I_{2}\right) \underline{\text { has a }} \\
\text { positive impact on the travel agencies' efficiency EFF. }\end{array}$ \\
$H_{3}:$ & $\begin{array}{l}\text { El between the insurance companies and the travel agencies }\left(E I_{3}\right) \text { has a positive } \\
\text { impact on the travel agencies' efficiency EFF. }\end{array}$ \\
\hline
\end{tabular}

C. Survey and collection of samples

The survey was conducted among 671 Croatian agencies, located along the Slovenian and northern Croatian coast. The agencies were generally smaller ones, concerning the number of employees. Their characteristics are given in Table 3.

As it turned out, only 64 questionnaires were fully completed and included in the research. The reasons for a low number of totally fulfilled questionnaires might be hidden in the awareness that the agencies were unwilling to disclose sensitive information about their economic activities.

However, although the relatively small sample size does not offer entirely optimal circumstances for the further statistical analysis, there have been several studies identified in the literature, confronted with this issue (for instance, they had years or countries as observed units). In these studies, it has been reported that the employed statistical estimation methods successfully completed their job regardless of the small sample size (Hox, 1998; Hoyle, 1995; Kenny, 2014; Müller, Bühner, \& Ellgring, 2003; Weston, 2006).

Table 3. Characteristics of the observed travel agencies.

\begin{tabular}{cccc}
\hline $\begin{array}{c}\text { Number of } \\
\text { employees }\end{array}$ & $\begin{array}{c}\text { Percentage } \\
\text { (\%) }\end{array}$ & $\begin{array}{c}\text { Work } \\
\text { experience } \\
\text { (in years) }\end{array}$ & $\begin{array}{c}\text { Percentage } \\
\text { (\%) }\end{array}$ \\
\hline $\mathbf{1 - 5}$ & 69 & $<5$ & 14.8 \\
$\mathbf{5}-\mathbf{1 0}$ & 12 & $5-10$ & 29.7 \\
$\mathbf{1 0}-\mathbf{2 0}$ & 8 & $10-20$ & 34.6 \\
$>\mathbf{2 0}$ & 11 & $>20$ & 22.9 \\
\hline
\end{tabular}




\section{METHODOLOGY}

\section{A. Methods}

Fig. 2 shows the methods used in the SEM modeling process. Firstly, the DEA analysis was conducted to estimate the efficiencies of the agencies. Here, the linear programming principles were applied for measuring the efficiency of a given decision-making unit (DMU) (Cooper et al., 2006; Fuentes, 2011). The most efficient DMU (i.e. company or some other organization) characterizes the "frontier", with which the relative performance of all other decision-making units in the sample must be compared. If there is any deviation of any DMU from the frontier, then such deviation is reflected as inefficiency.

Afterwards, the EFA analysis was applied to determine the factor model structure from the given data. The factor model has given us preliminary information, how the latent factors $E I_{i}, i=1,2,3$ can be assessed via the observation of measured indicator items $T_{i}, A_{i}, I_{i}$.

Subsequently, the CFA analysis aided us to confirm the hypothesized EFA based factor structure, where a measurement part of SEM model was also derived. This way, the CFA statistically evaluated the correctness of estimated relationships between the latent factors $E I_{i}, i=1,2,3$ and their observed indicators $T_{i}, A_{i}, I_{i}$.

Finally, the SEM modeling procedure was executed, with a derived structural part of the SEM model as the main result. Here, both sub-models, measurement and structural, were also combined together and converted into the overall SEM model. By doing this, the final SEM model has revealed the causal path relations between the constructs $E I_{i}, i=1,2,3$ on one side, and the factor representing the efficiency EFF on the other.

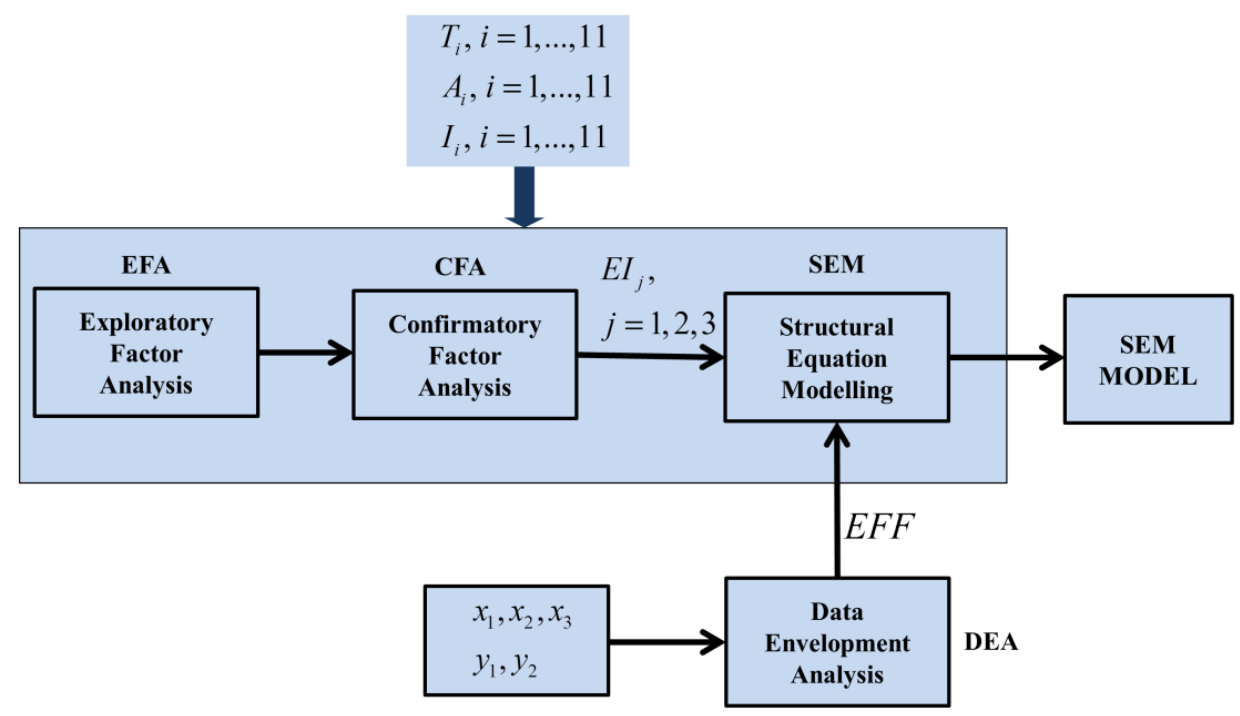

Figure 2. The methodological framework (the CFA gives the measurement part, while the SEM procedure provides the structural part of the SEM model).

\section{B. Estimators}

In order to estimate model's parameters in the CFA and SEM procedures, several estimation methods have been derived during the last decades (Byrne, 2009; Hair, 2010; Hoyle, 2012; Kline, 
2005). The most common one is the maximum likelihood estimator (MLE), usually used in the case of at least approximately normally distributed data.

This kind of estimator was also used in our case, since the assumption about non-normality of the relevant indicator variables was only slightly violated (see Appendix 2). The justification for employing the MLE estimator is based on the conclusions of several other studies. Namely, in these studies it is stated that the MLE estimator calculates suitably accurate parameters, if the ordinal indicator data contain at least five stages and are approximately normal (El-Basyouny \& El-Bassiouni, 2013; Hoyle, 2012).

\section{RESULTS}

The analysis of normality and the EFA analysis were conducted by the means of statistical package SPSS 21, while the CFA analysis and the structural equation modeling have been performed in the AMOS environment. The DEA has been executed by using the LINGO software.

\section{A. Descriptive statistics and normality}

The arithmetic mean, standard deviation (SD), skewness index (SI), and kurtosis index (KI) of the applied indicators are shown in Appendix 2. The level of non-normality is usually investigated by calculating the skewness index (SI) and kurtosis index (KI) of the given data.

In the existing literature, there is some disagreement about the most proper criterions regarding the non-normality level, which is still acceptable for an efficient use of the MLE estimator. Nevertheless, in general, the scholars agree that the values $|S I|<3$ and $|K I|<7$ are still permissible to apply a MLE method without any serious concerns, even in the case of relatively small sample size (Kline, 2005; Lei \& Lomax, 2005; Ullman, 2006; Weston, 2006; Zhai, 2013).

In our study, the normality conditions about the data were not severely violated, since we had: $\left|S I_{i t e m s}\right|<2.01,\left|K I_{\text {items }}\right|<6.51$ (see Appendix 2). Accordingly, while conducting the CFA and SEM, we have decided to use the MLE estimator, since the latter provides quite big spectra of various Goodness-of-fit (GOF) indices needed during the model validation process.

\section{B. Factor analysis}

While doing the factor analysis, the EFA was applied as a beginning step. Here, two tests were first conducted, the Kaiser-Meyer-Olkin (KMO) test, and the Bartlett's test of sphericity (BTS) (Hair, 2010; Hoyle, 2012; Kline, 2005). It turned out that the BTS value was adequately significant ( $\chi^{2}=960.346$ with $d f=91$ and $p<0.001$ ), while the KMO value also reached an appropriate level: $0.868>0.5$ . Accordingly, with the recommendation of several authors in mind (Frohlich \& Westbrook, 2001; Li ef al., 2013; Sahin, Todiras, Nijkamp, Neuts, \& Behrens, 2012), we concluded that the EFA can be consistently conducted in the further research.

Some important details of the EFA analysis are shown in Table 4. The principle axis factoring (PAF) method was applied to extract the factors and estimate their loadings. Since the communalities $h_{i}^{2}$ of some indicator items were not acceptable, as well as the cross-loadings were significant, 19 illfitting items were dropped from the further analysis.

Afterwards, the PAF method was conducted again, with an additional use of the rotation based on Promax method with Kaiser Normalization. We have used three criterions for choosing the optimal number of extracted factors: the Kaiser's "Eigen value bigger than one rule", the Cattell's scree plot, and the computation of the percentage of variation (Hoyle, 2012; Kline, 2005). In the final factor model, only those indicator items were retained, which are significantly loaded on their factors (which means: loadings $\lambda_{i j} \geq 0.795>0.40$, according to (Hair, 2010)). 
The adequacy of the derived factor model can be verified in the table in Appendix 3. Here, the rotated factor pattern matrix with the item loadings on corresponding factors is presented. Since the Cronbach alphas of all exposed factors are bigger than the recommended value 0.7 (according to (Hair, 2010)), we have concluded that the reliability and internal consistency are adequate.

Table 4. Characteristics of the EFA analysis.

\begin{tabular}{|c|c|}
\hline \multicolumn{2}{|c|}{ Characteristics of EFA } \\
\hline 1. Initial Estimation & \\
\hline Unrotated extraction (estimation) method: & Principal Axis Factoring (PAF) \\
\hline Dropped ill-fitting items from the analysis: & $\begin{array}{l}A_{1}, A_{2}, A_{8}, A_{9}, A_{10}, A_{11} \\
I_{1}, I_{8}, I_{9}, I_{10}, I_{11} \\
T_{1}, T_{3}, T_{4}, T_{7}, T_{8}, T_{9}, T_{10}, T_{11}\end{array}$ \\
\hline 2. Estimation with additional rotation (retained variables) & \\
\hline Extraction (estimation) method: & Principal Axis Factoring (PAF) \\
\hline Rotation method: & PROMAX with Kaiser Normalization \\
\hline Optimal number of factors extracted and retained: $\mathbf{3}$ & $\begin{array}{l}\text { Criterions: } \\
\text { - Kaiser's "Eigen value bigger than } \\
\text { one rule", } \\
\text { - Cattell's scree plot, } \\
\text { - } \quad \text { Percentage of Variation } \\
\quad \text { Criterion (PVC). }\end{array}$ \\
\hline Final loadings $\lambda_{i j}$ and convergent validity (CV): & $\lambda_{i j} \geq 0.795$ (CV is adequate) \\
\hline Communalities $h_{i}^{2}$ of the retained variables (range): & $0.569 \leq h_{i}^{2} \leq 0.948$ (sufficiently large) \\
\hline
\end{tabular}

The CFA analysis was employed as a next step in the factor analysis. Within this framework, the measurement part of the SEM model was also derived in the context of the first stage of SEM model construction. Here, the structure of the previously calculated factor model from the EFA analysis was applied as a starting point. The CFA tested if the structure of the factor model is consistent with the measurement theory. For this purpose, the MLE method was used to estimate model parameters in such way, that the difference between the model implied covariance matrix, and the data-based covariance matrix, was minimized (Hoyle, 2012).

When the allocation of indicator items on their factors was successfully completed, the fitting performance of the derived CFA factor model was investigated in the next step. To do so, several model fit indices, typically suggested in the literature, were calculated, such as: the Comparative Fit Index (CFI), the Incremental fit index (IFI), the Tucker-Lewis index (TLI), the Normed fit index (NFI), the Root Mean Square Error of Approximation (RMSEA), and the Standardized Root Mean Residual (SRMR) (Byrne, 2009). It turned out that all of these indices were adequate with respect to their threshold ranges, suggested in the literature (Hair, 2010; Hooper, 2008; Hoyle, 2012; Kline, 2005).

The CFA analysis was completed by accessing the convergent and discriminant validity of the corresponding model. The convergent validity was inspected via the calculation of composite reliability (CR) and average variance extracted (AVE). According to Hair and his colleagues (Hair, 2010), the appropriate threshold levels of these two measures are: 0.70 for $C R$, and 0.5 for AVE. Table 5 shows that the CR and AVE values of all treated factors were above their threshold level, which indicates a satisfied convergent validity of the model. 
When addressing the discriminant validity, the following condition must be fulfilled for each factor: $A V E>C O R R^{2}$, or $\sqrt{A V E}>C O R R$ (Fornell \& Larcker, 1981; Hair, 2010), where CORR refers to the cross-correlations between factors. From Table 5 it can be seen that the condition $\sqrt{A V E}>C O R R$ was satisfied for each cross-correlation pair of the factors. Since the discriminant validity öf the model was also adequate, we have concluded that there were no model's validity concerns.

When the CFA analysis was finalized, its main result, the measurement part of the structural equation model, was applied in the further SEM modeling process.

Table 5. Convergent and discriminant validity of the CFA model.

\begin{tabular}{cccccc}
\hline & $\mathbf{C R}$ & $\begin{array}{c}\mathbf{A V E} \\
(\sqrt{A V E})\end{array}$ & $E I_{I}$ & $E I_{A}$ & $E I_{T}$ \\
\hline$E I_{I}$ & $\mathbf{0 . 9 4 9}$ & $\mathbf{0 . 8 3 6}$ & $\sqrt{A V E}=0.914$ & & \\
& & $\mathbf{( 0 . 9 1 4})$ & & & \\
$E I_{A}$ & $\mathbf{0 . 9 6 8}$ & $\mathbf{0 . 7 8 8}$ & CORR $=0.482$ & $\sqrt{A V E}=0.888$ & \\
& & $\mathbf{( 0 . 8 8 8})$ & & & \\
$E I_{T}$ & $\mathbf{0 . 8 7 4}$ & $\mathbf{0 . 6 9 9}$ & CORR $=0.629$ & CORR $=0.363$ & $\sqrt{A V E}=0.836$ \\
& & $\mathbf{( 0 . 8 3 6}$ & & & \\
\hline
\end{tabular}

\section{Structural equation model}

The structural equation modelling represented a second stage of the SEM model construction. Here, the structural part of the SEM model has also been derived. The combination of both parts, structural one, and measurement one, has given us the entire structure of the SEM model, conceptually consistent with the framework from Figure 1. Accordingly, the single-item construct representing the efficiency EFF was also integrated into the SEM model as hypothesized in Figure 1 and Figure 2.

During the structural equation modelling, the parameters of the overall SEM model were estimated by the means of the MLE. Moreover, the directed causal paths between the addressed factors were also identified. Similarly as in the case of the CFA, several fit indices were calculated to investigate the model's adequacy. Table 6 shows in its rightmost column the calculated values of the most important fit indices. According to the recommendations of many scholars (e.g. (Byrne, 2009; Hair, 2010; Hoyle, 2012; Kline, 2005; Nunkoo \& Ramkissoon, 2012)l, the fit indices have taken the adequate values regarding their threshold values. Hence, we assumed that the derived SEM model can provide the reasonably good fit to the real data.

Table 6. Fit indices of the derived SEM model.

\begin{tabular}{|c|c|c|c|}
\hline Fit Index & Description & Acceptable Threshold Levels & Value \\
\hline$\chi^{2}$ & $\begin{array}{l}\text { Chi-Square } \chi^{2} \text { of the discrepancy } \\
\text { between the sample and the fitted } \\
\text { covariances' matrices }\end{array}$ & $\begin{array}{l}\text { Low value relative to } \\
\text { degrees of freedom } d f\end{array}$ & 83.787 \\
\hline$\left(\chi^{2} / d f\right)$ & $\begin{array}{l}\text { Relative Chi-Square } \chi^{2} \text { of the } \\
\text { discrepancy }\end{array}$ & $\begin{array}{ll}<3 & \text { good } \\
<5 & \text { permissible }\end{array}$ & 1.102 \\
\hline RMSEA & $\begin{array}{l}\text { Root Mean Square Error of } \\
\text { Approximation }\end{array}$ & $\begin{array}{ll}<0.07 & \text { good } \\
0.07 \square 0.10 & \text { moderate } \\
>0.10 & \text { bad }\end{array}$ & 0.041 \\
\hline
\end{tabular}


Logistics \& Sustainable Transport

Vol. 7, No. 1, October 2016, 1-17

doi: 10.1515/jlst-2016-0001

\begin{tabular}{|c|c|c|c|c|}
\hline NFI & Normed-fit Index & $\begin{array}{l}>0.90 \\
>0.95\end{array}$ & $\begin{array}{l}\text { acceptable } \\
\text { good }\end{array}$ & 0.923 \\
\hline $\begin{array}{l}\text { NNFI } \\
(\text { TLI) }\end{array}$ & $\begin{array}{l}\text { Non-Normed-fit Index (Tucker-Lewis } \\
\text { Index) }\end{array}$ & $\begin{array}{l}>0.95 \\
>0.90\end{array}$ & $\begin{array}{l}\text { good } \\
\text { acceptable }\end{array}$ & 0.989 \\
\hline CFI & Comparative Fit Index & $\begin{array}{l}>0.90 \\
>0.95\end{array}$ & $\begin{array}{l}\text { acceptable } \\
\text { good }\end{array}$ & 0.992 \\
\hline IFI & Bollen's Incremental Fit Index & $\begin{array}{l}>0.90 \\
>0.95\end{array}$ & $\begin{array}{l}\text { acceptable } \\
\text { good }\end{array}$ & 0.992 \\
\hline SRMR & $\begin{array}{l}\text { Standardized Root Mean Square } \\
\text { Residual }\end{array}$ & $<0.08$ & good & 0.0586 \\
\hline
\end{tabular}

Fig. 3 illustrates the standardized SEM model with the estimated path coefficients significant at $p \leq 0.10$ level. This model corresponds to the conceptual hypothesized framework from Fig. 1. The numbers $0.32,0.31$, and 0.47 , linked with the underlying directional paths, represent the standardized regression weights.

In Fig. 3, the retained indicator items are also shown. The causal paths that link the factors $E I_{I}, E I_{A}, E I_{T}$ with the construct $E F F$, contain positive and statistically significant regression weights. Accordingly, we can conclude that all presumed hypotheses $H_{1}, H_{2}, H_{3}$ from Table 2 are confirmed (see Table 7). By other words, the agencies' external integrations with the other SC members indeed have a certain impact on the agencies' efficiency.

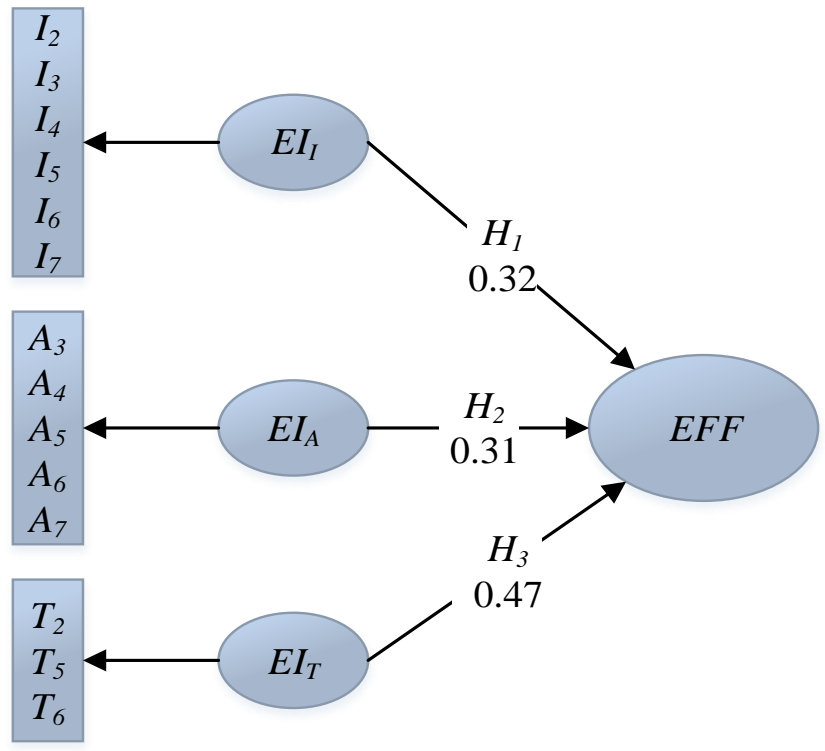

Figure 3. The standardized estimated SEM model.

Table 7. Confirmation of the presumed hypotheses.

\begin{tabular}{ccc}
\hline $\begin{array}{l}\text { Notation of } \\
\text { Hypothesis }\end{array}$ & The Content of the hypothesis & $\begin{array}{c}\text { Confirmation } \\
\text { of hypothesis }\end{array}$ \\
\hline$H_{1}:$ & $E I_{T}$ has a positive impact on the travel agencies' efficiency EFF. & $\begin{array}{c}\text { Accepted } \\
\text { (supported) }\end{array}$ \\
$H_{2}:$ & $E I_{A}$ has a positive impact on the travel agencies' efficiency EFF. & $\begin{array}{c}\text { Accepted } \\
\text { (supported) }\end{array}$ \\
\hline
\end{tabular}




$$
H_{3}: \quad E I_{I} \text { has a positive impact on the travel agencies' efficiency EFF. }
$$

\section{Discussion}

From the descriptive statistics of an applied indicators in Appendix 2 can be seen that the agencies still most frequently collaborate with the other SC members on some more basic level (e.g. Phone, e-mail). Conversely, the deeper forms of collaboration, such as joint planning and setting of goals, joint development, and understanding of responsibility, as well as aligned decisions about improving the cost efficiency, are maybe too much neglected.

However, on the other side, the developed SEM model suggests (see the retained indicators in Fig. 3), that it is precisely such deeper form of cooperation needed to be amplified not only to influence positively on the efficiency, but also to accomplish such goal in the most effective manner. Hence, the level of integration, increased due to in-depth forms of cooperation would also lead to better exploitation of the identified positive interaction between the El factors and efficiency of the agencies.

\section{CONCLUSION}

Nowadays, the supply chain integration is becoming progressively important due to the increased complexity of environments, globalization effects, and the rising demands of customers. This is particularly true for the service sector with numerous supply chain members involved, where the quality of services must be increased as much as possible to ensure the maximal customer satisfaction.

The tourism sector is also one of the service industries that is essentially dependent on the customer satisfaction. To provide maximal possible quality to the customers, some forms of cooperation and integration between the supply chain members are unavoidable. Integration with the other supply chain members is also essential for the travel agencies as crucial members of tourism supply chains. This is not true only in a context of satisfying the customers' demands, but also to increase the agencies' efficiency in the largest possible manner.

In this paper, we have analyzed the relationships between the agencies' external integration with other supply chain members on one side, and their efficiency on the other. In the role of other supply chain members, the following members were employed: the accommodation companies, the insurance companies, the tour operators, and the other travel agencies.

In the course of research, the data from 64 Croatian agencies positioned along the north-eastern Adriatic Sea were treated. For the computation of the agencies' efficiencies, the data envelopment analysis was applied, while for the further analysis, the structural equation model was constructed. The model exposed the relationships between the external integrations' constructs, and the construct related to the agencies' efficiency.

The results show that an amplified external integration with other supply chain members might indeed have certain positive impacts on increased efficiency of the travel agencies. Moreover, the constructed SEM model implies that deeper forms of cooperation needed to be enforced not only to influence positively on the efficiency, but also to achieve such objective in the most efficient way. Accordingly, the integration level, risen due to in-depth forms of collaboration would also lead to the more efficient exploitation of the recognized positive interrelations between the external integration and efficiency of the travel agencies.

This conclusion could be a very motivating guideline for the management of the agencies in the sense of creating suitable integration strategies to achieve higher profits and a bigger number of customers, as well as to reduce the levels of costs. Also, better investment strategies and potential improvements in the operations management are more likely to be achieved as a result of the increased external integration with other supply chain members. 
Since there is a quite big gap detected in the literature which addresses a similar type of research, we believe that our study might have brought some contribution to the existing literature on the topic.

One of the possible directions for future research could be the testing of the structural equation model for other travel agencies to examine the adequacy of the findings argued in this paper. Studying the agencies of the other countries, as well as whole regional areas is also intended to be carried out in future work.

\section{REFERENCES}

Alamdari, Fariba. (2002). Regional development in airlines and travel agents relationship. Journal of Air Transport Management, 8(5), 339-348. doi: 10.1016/s0969-6997(02)00014-5

Assaf, A., Barros, C. P., \& Josiassen, A. (2010). Hotel efficiency: A bootstrapped metafrontier approach. International Journal of Hospitality Management, 29(3), 468-475. doi: 10.1016/j.jijhm.2009.10.020

Assaf, A. George, Barros, Carlos Pestana, \& Dieke, Peter U. C. (2011). Portuguese tour operators: A fight for survival. Journal of Air Transport Management, 17(3), 155-157. doi: 10.1016/j.jairtraman.2010.12.002

Assaf, A. George, \& Magnini, Vincent. (2012). Accounting for customer satisfaction in measuring hotel efficiency: Evidence from the US hotel industry. International Journal of Hospitality Management, 31 (3), 642-647. doi: 10.1016/j.jijmm.2011.08.008

Atkinson, Helen, \& Brander Brown, Jackie. (2001). Rethinking performance measures: assessing progress in UK hotels. Int J Contemp Hospitality Mngt, 13(3), 128-136. doi: 10.1 108/09596110110388918

Bastakis, Constantinos, Buhalis, Dimitrios, \& Butler, Richard. (2004). The perception of small and medium sized tourism accommodation providers on the impacts of the tour operators' power in Eastern Mediterranean. Tourism Management, 25 (2), 151-170. doi: 10.1016/s0261-5177(03)00098-0

Bull, A. (1995). The Economics of Travel and Tourism. London: Longman.

Byrne, B.M. (2009). Structural Equation Modeling With AMOS: Basic Concepts, Applications, and Programming. London: Routledge.

Cooper, W., Seiford, L., \& Tone, L. (2006). Data Envelopment Analysis, A comprehensive text with models, applications, references and DEA-solver software. Massachusetts: Kluwer Academic Publishers.

Council, World Travel \& Tourism. (2014). Travel \& Tourism: Economic Impact 2014. London: WTTC.

Denise, L. (2007). Collaboration vs. C- Three (Cooperation, Coordination, and Communication). Innovating, 7 (3), $1-5$.

Dragan, D., Kramberger, T., \& Topolšek, D. . (2015). Supply chain integration and firm performance in the tourism sector. Paper presented at the Pre-conference proceedings of the 12th International Conference on Logistics \& Sustainable Transport 2015, Celje.

El-Basyouny, Karim, \& El-Bassiouni, Mohamed Yahia. (2013). Modeling and analyzing traffic safety perceptions: An application to the speed limit reduction pilot project in Edmonton, Alberta. Accident Analysis \& Prevention, 51, 156-167. doi: 10.1016/j.aap.2012.11.009

Ellinger, A. E., Daugherty, P. J., \& Scott, B. K. . (2000).). The Relationship between Marketing/Logistics Interdepartmental Integration and Performance in U.S. Manufacturing Firms: An Empirical Study. Journal of Business Logistics, 21 (1), 1-22.

Enz, Cathy A., Canina, Linda, \& Walsh, Kate. (2001). Hotel-industry Averages: An Inaccurate Tool for Measuring Performance. The Cornell Hotel and Restaurant Administration Quarterly, 42(6), 22-32. doi: $10.1177 / 0010880401426002$

Evans, N. (2003). Strategic methods of development for travel and tourism: Elsevier BV.

Flynn, Barbara B., Huo, Baofeng, \& Zhao, Xiande. (2010). The impact of supply chain integration on performance: A contingency and configuration approach. Journal of Operations Management, 28 (1), 58-71. doi: 10.1016/j.jom.2009.06.001

Fornell, Claes, \& Larcker, David F. (1981). Evaluating Structural Equation Models with Unobservable Variables and Measurement Error. Journal of Marketing Research, 18(1), 39. doi: 10.2307/3151312

Frohlich, Markham T., \& Westbrook, Roy. (2001). Arcs of integration: an international study of supply chain strategies. Journal of Operations Management, 19(2), 185-200. doi: 10.1016/s0272-6963(00)00055-3

Fuentes, Ramón. (2011). Efficiency of travel agencies: A case study of Alicante, Spain. Tourism Management, 32 (1), 75-87. doi: 10.1016/j.tourman.2009.12.003

Gimenez, Cristina, \& Ventura, Eva. (2005). Logistics-production, logistics-marketing and external integration. Int Jrnl of Op \& Prod Mnagemnt, 25 (1), 20-38. doi: 10.1108/01443570510572222

Griffin, Abbie, \& Hauser, John R. (1996). Integrating R\&D and Marketing: A Review and Analysis of the Literature. Journal of Product Innovation Management, 13(3), 191-215. doi: 10.1111/1540-5885.1330191

Group, European People's Party. (2012). Building Europe 2020 in Partnership: Tourism as a driver for smart, sustainable and inclusive growth. Brussels: EPP Group in the Committee of Regions.

Hair, J. F, Black, W. C, Babin, B. J, \& Anderson, R. E. . (2010). Multivariate Data Analysis. New Jersey: Prentice Hall. 
Heshmati, Almas. (2003). Productivity Growth, Efficiency and Outsourcing in Manufacturing and Service Industries. Journal of Economic Surveys, 17(1), 79-112. doi: 10.1111/1467-6419.00189

Hooper, D., Coughlan, J., \& Mullen, M. R. (2008). (2008). Structural equation modelling: Guidelines for determining model fit. Electronic Journal of Business Research Methods, 17(1), 79-112.

Hox, J. J, \& Bechger, T. M. . (1998). An introduction to structural equation modeling. Family Science Review, 11 , 354-373.

Hoyle, R. H. . (1995). Structural Equation Modeling: Concepts, Issues, and Applications. Thousand Oaks: Sage.

Hoyle, R. H. . (2012). Handbook of Structural Equation Modeling. New York: The Guilford Press.

Kenny, D. A. . (2014). Measuring Model Fit. Retrieved February 6, 2014, from http://davidakenny.net/cm/fit.htm

Kline, R. B. . (2005). Principles and Practice of Structural Equation Modeling New Zork: The Guilford Press.

Kovačić, Nataša, Topolšek, Darja, \& Dragan, Dejan. (2015). Tourism sector, Travel agencies, and Transport Suppliers: Comparison of Different Estimators in the Structural Equation Modeling. Logistics \& Sustainable Transport, 6(1). doi: 10.1515/jlst-2015-0007

Lafferty, George, \& Fossen, Anthony van. (2001). Integrating the tourism industry: problems and strategies. Tourism Management, 22 (1), 11-19. doi: 10.1016/s0261-5177(00)00021-2

Lee, H. E. . (2000). Creating Value through Supply Chain Integration. Supply Chain Management Review, 9(1), 30-37.

Lei, Ming, \& Lomax, Richard G. (2005). The Effect of Varying Degrees of Nonnormality in Structural Equation Modeling. Structural Equation Modeling: A Multidisciplinary Journal, 12(1), 1-27. doi: 10.1207/s15328007sem1201_1

Lemmetyinen, A. . (2010). Coordination of cooperation in tourism business networks. (PhD), Turku School of Economics, Turku.

Li, Juan, Zhou, Lanshu, Zhu, Daqiao, Hu, Chen, Zhang, Xiaoyun, \& Xu, Yan. (2013). Chinese version of the nursing students' perception of instructor caring (C-NSPIC): Assessment of reliability and validity. Nurse Education Today, 33(12), 1482-1489. doi: 10.1016/j.nedt.2013.05.017

Liang, L. T., Yang, J. T. . (2012). Analysis of the tourism efficiency and its decomposition based on DEA. Geographical Research, 31 (8), 1422-1430.

Liang, M., Yi, T. . (2012). An Evaluation and Analysis of Tourism Efficiency in Different Cities and Regions of Guangdong Province. Economic Geography, 10, 371-383.

Manasakis, Constantine, Apostolakis, Alexandros, \& Datseris, George. (2013). Using data envelopment analysis to measure hotel efficiency in Crete. Int J Contemp Hospitality Mngt, 25(4), 510-535. doi: $10.1108 / 09596111311322907$

Mclaughlin, Curtis P., \& Coffey, Sydney. (1990). Measuring Productivity in Services. Int J of Service Industry Mgmt, 1 (1), 46-64. doi: 10.1 108/09564239010002847

Medina-Muñoz, Diego, \& García-Falcón, Juan Manuel. (2000). Successful relationships between hotels and agencies. Annals of Tourism Research, 27(3), 737-762. doi: 10.1016/s0160-7383(99)00104-8

Mia, Lokman, \& Patiar, Anoop. (2001). The use of management accounting systems in hotels: an exploratory study. International Journal of Hospitality Management, 20(2), 111-128. doi: 10.1016/s0278$4319(00) 00033-5$

Müller, Jochen, Bühner, Markus, \& Ellgring, Heiner. (2003). Is there a reliable factorial structure in the 20-item Toronto Alexithymia Scale? Journal of Psychosomatic Research, 55(6), 561-568. doi: 10.1016/s00223999 (03)00033-3

Nunkoo, Robin, \& Ramkissoon, Haywantee. (2012). Structural equation modelling and regression analysis in tourism research. Current Issues in Tourism, 15(8), 777-802. doi: 10.1080/13683500.2011.641947

Phillips, Paul A. (1999). Hotel performance and competitive advantage: a contingency approach. Int J Contemp Hospitality Mngt, 11 (7), 359-365. doi: 10.1108/09596119910293268

Rinehart, Lloyd M., Bixby Cooper, M., \& Wagenheim, George D. (1989). Furthering the integration of marketing and logistics through customer service in the channel. Journal of the Academy of Marketing Science, 17(1), 63-71. doi: 10.1007/bf02726355

Sahin, Mediha, Todiras, Alina, Nijkamp, Peter, Neuts, Bart, \& Behrens, Christiaan. (2012). A Structural Equations Model for Assessing the Economic Performance of High-tech Ethnic Entrepreneurs Globalization Trends and Regional Development: Edward Elgar Publishing.

Shang, Jui-Kou, Wang, Fei-Ching, \& Hung, Wei-Ting. (2010). A stochastic DEA study of hotel efficiency. Applied Economics, 42 (19), 2505-2518. doi: 10.1080/00036840701858091

Sigala, Marianna. (2008). A supply chain management approach for investigating the role of tour operators on sustainable tourism: the case of TUI. Journal of Cleaner Production, 16(15), 1589-1599. doi: 10.1016/j.jclepro.2008.04.021

Singh, L. K. . (2008). Management of Travel Agency. Delhi: ISHA Books.

Stock, Gregory N., Greis, Noel P., \& Kasarda, John D. (2000). Enterprise logistics and supply chain structure: the role of fit. Journal of Operations Management, 18(5), 531-547. doi: 10.1016/s0272-6963(00)00035-8

Suzuki, Soushi, Nijkamp, Peter, \& Rietveld, Piet. (2011). Regional efficiency improvement by means of data envelopment analysis through Euclidean distance minimization including fixed input factors: An 
application to tourist regions in Italy. Papers in Regional Science, 90(1), 67-89. doi: 10.1111/j.14355957.2010.00316.x

Tapper, R., Font, X. (2004). Tourism Supply chains: Report of a desk research project for the Travel Foundation Environment Business and Development Group. Leeds: Leeds Metropolitan University.

Thea Sinclair, M., \& Stabler, Mike. (1997). The Economics of Tourism Routledge Advances in Tourism: Routledge.

Theuvsen, Ludwig. (2004). Vertical Integration in the European Package Tour Business. Annals of Tourism Research, 31 (2), 475-478. doi: 10.1016/j.annals.2003.12.007

Topolšek, Darja, Čižman, Anton, \& Lipičnik, Martin. (2010). Collaborative Behaviour as a Facilitator of Integration of Logistic and Marketing Functions - The Case of Slovene Retailers. PROMET - Traffic\&Transportation, 22 (5). doi: $10.7307 /$ ptt.v22i5.200

Topolšek, Darja, Kovačić, Nataša, \& Cvahte, Tina. (2014). Travel Agencies' External Integration. Paper presented at the The 8th International Scientific Conference "Business and Management 2014". http://dx.doi.org/10.3846/bm.2014.094

Topolšek, Darja, Mrnjavac, Edna, \& Kovačić, Nataša. (2014). Integration of travel agencies with transport providers. Tourism Management Perspectives, 9, 14-23. doi: 10.1016/j.tmp.2013.11.003

Tsaur, S. H. (2006). The Relational Behavior Between Wholesaler and Retailer Travel Agencies: Evidence From Taiwan. Journal of Hospitality \& Tourism Research, 30 (3), 333-353. doi: 10.1177/1096348006286796

Ullman, Jodie B. (2006). Structural Equation Modeling: Reviewing the Basics and Moving Forward. Journal of Personality Assessment, 87 (1), 35-50. doi: 10.1207/s15327752jpa8701_03

Véronneau, Simon, \& Roy, Jacques. (2009). Global service supply chains: An empirical study of current practices and challenges of a cruise line corporation. Tourism Management, 30(1), 128-139. doi: 10.1016/j.tourman.2008.05.008

Vickery, Shawnee K., Jayaram, Jayanth, Droge, Cornelia, \& Calantone, Roger. (2003). The effects of an integrative supply chain strategy on customer service and financial performance: an analysis of direct versus indirect relationships. Journal of Operations Management, $21(5)$, 523-539. doi: 10.1016/j.jom.2003.02.002

Wang, K., Huang, Z., Tao, Y., \& Fang, Y. . (2013). Study on Spatial Characteristics and Spillover Effects of Urban Tourism Efficiency: A Case of Yangtze River Delta. Economic Geography, 4, 161-174.

Weston, R. (2006). A Brief Guide to Structural Equation Modeling. The Counseling Psychologist, 34 (5), $719-751$. doi: $10.1177 / 0011000006286345$

Yan, C. (2013). An Improved City Tourism Efficiency Evaluation Model Based on Data Envelopment Analysis. International Journal of Digital Content Technology and its Applications, $7(2), 343-349$.

Yi, Tingting, \& Liang, Mingzhu. (2014). Evolutional Model of Tourism Efficiency Based on the DEA Method: A Case Study of Cities in Guangdong Province, China. Asia Pacific Journal of Tourism Research, 20 (7), 789-806. doi: 10.1080/10941665.2014.932294

Yllmaz, Yldirım, \& Bititci, Umit S. (2006). Performance measurement in tourism: a value chain model. Int J Contemp Hospitality Mngt, 18(4), 341-349. doi: 10.1108/09596110610665348

Zhai, X., Liu, A. M. M, \& Fellows, R. (2013). Human Resource Practices in Chinese Construction Organizations: Development of a Measurement Scale. International Journal of Architecture, Engineering and Construction, $2(3), 170-183$.

Zhang, Xinyan, Song, Haiyan, \& Huang, George Q. (2009). Tourism supply chain management: A new research agenda. Tourism Management, 30 (3), 345-358. doi: 10.1016/j.tourman.2008.12.010

Appendix 1. The levels of integration considered (questions of the first part of the questionnaire).

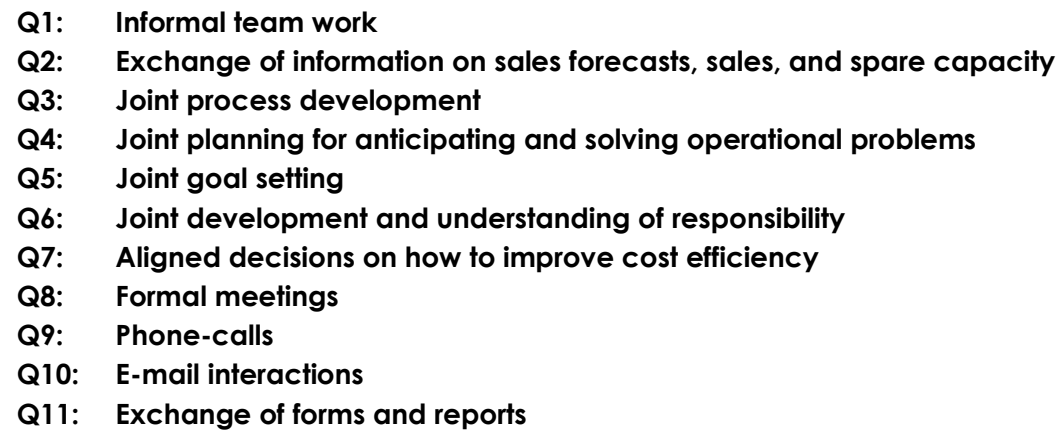


Appendix 2. Descriptive statistics for the applied indicator variables.

Descriptive statistics (EI between TOUR OPERATORS/OTHER TRAVEL AGENCIES and the travel agencies)

\begin{tabular}{|c|c|c|c|c|c|}
\hline Variable - description & Variable & Mean & SD & Skewness & Kurtosis \\
\hline Informal team work & $T_{1}$ & 2.84 & 1.200 & -.092 & -.951 \\
\hline $\begin{array}{l}\text { Exchange of information on sales forecasts. sales and } \\
\text { spare capacities }\end{array}$ & $T_{2}$ & 3.48 & 1.337 & -.552 & -.745 \\
\hline Joint process development & $T_{3}$ & 2.75 & 1.513 & .195 & -1.434 \\
\hline $\begin{array}{l}\text { Joint planning for anticipating and solving operational } \\
\text { problems }\end{array}$ & $T_{4}$ & 2.84 & 1.440 & -.015 & -1.320 \\
\hline Joint setting of goals & $T_{5}$ & 2.93 & 1.504 & -.037 & -1.434 \\
\hline Joint development and understanding of responsibility & $T_{6}$ & 3.23 & 1.553 & -.315 & -1.382 \\
\hline Aligned decisions on how to improve cost efficiency & $T_{7}$ & 3.11 & 1.561 & -.170 & -1.454 \\
\hline Formal meeting & $T_{8}$ & 3.10 & 1.457 & -.143 & -1.299 \\
\hline Phone call & $T_{9}$ & 4.36 & .932 & -1.944 & 4.327 \\
\hline E-mail & $T_{10}$ & 4.65 & .68 & -2.019 & 6.509 \\
\hline Exchange of forms and reports & $T_{11}$ & 3.34 & 1.580 & -.307 & -1.482 \\
\hline
\end{tabular}

\section{Descriptive statistics (El between ACCOMODATIONS and the travel agencies)}

\begin{tabular}{lccccc} 
Variable - description & Variable & Mean & SD & Skewness & Kurtosis \\
\hline Informal team work & $A_{1}$ & 2.90 & 1.434 & -.032 & -1.194 \\
$\begin{array}{l}\text { Exchange of information on sales forecasts. sales and } \\
\text { spare capacities }\end{array}$ & $A_{2}$ & 3.25 & 1.502 & -.436 & -1.222 \\
Joint process development & $A_{3}$ & 2.62 & 1.474 & .235 & -1.389 \\
$\begin{array}{l}\text { Joint planning for anticipating and solving operational } \\
\text { problems }\end{array}$ & $A_{4}$ & 2.87 & 1.554 & .033 & -1.481 \\
Joint setting of goals & $A_{5}$ & 2.75 & 1.513 & .076 & -1.517 \\
Joint development and understanding of responsibility & $A_{6}$ & 2.77 & 1.553 & .177 & -1.507 \\
Aligned decisions on how to improve cost efficiency & $A_{7}$ & 2.77 & 1.532 & .257 & -1.414 \\
Formal meeting & $A_{8}$ & 3.34 & 1.459 & -.396 & -1.167 \\
Phone call & $A_{9}$ & 4.42 & 0.846 & -1.100 & 2.805 \\
E-mail & $A_{10}$ & 4.67 & .598 & -1.674 & 1.782 \\
Exchange of forms and reports & $A_{11}$ & 3.46 & 1.444 & -.413 & -1.218 \\
\hline
\end{tabular}

Descriptive statistics (EI between INSURANCE COMPANIES and the travel agencies)

\begin{tabular}{|c|c|c|c|c|c|}
\hline Variable - description & Variable & Mean & SD & Skewness & Kurtosis \\
\hline Informal team work & $l_{1}$ & 2.03 & 1.238 & .917 & -.283 \\
\hline $\begin{array}{l}\text { Exchange of information on sales forecasts. sales and } \\
\text { spare capacities }\end{array}$ & $I_{2}$ & 2.16 & 1.368 & .824 & -.679 \\
\hline Joint process development & $I_{3}$ & 2.18 & 1.443 & .842 & -.727 \\
\hline $\begin{array}{l}\text { Joint planning for anticipating and solving operational } \\
\text { problems }\end{array}$ & $l_{4}$ & 2.26 & 1.389 & .667 & -.847 \\
\hline Joint setting of goals & $I_{5}$ & 2.00 & 1.197 & .904 & -.341 \\
\hline Joint development and understanding of responsibility & 16 & 2.41 & 1.542 & .569 & -1.280 \\
\hline Aligned decisions on how to improve cost efficiency & $l_{7}$ & 2.13 & 1.443 & .933 & -.592 \\
\hline Formal meeting & 18 & 2.66 & 1.569 & .357 & -1.397 \\
\hline Phone call & 19 & 3.72 & 1.439 & -.878 & -.590 \\
\hline E-mail & $1 / 0$ & 3.89 & 1.415 & -1.067 & -.205 \\
\hline
\end{tabular}


Logistics \& Sustainable Transport

Vol. 7, No. 1, October 2016, 1-17

doi: 10.1515/jlst-2016-0001

\begin{tabular}{llllll}
\hline Exchange of forms and reports & 111 & 3.31 & 1.618 & -.356 & -1.479 \\
\hline
\end{tabular}

Appendix 3. The rotated factor pattern matrix from the EFA analysis.

\begin{tabular}{|c|c|c|c|}
\hline \multirow{2}{*}{ Pattern Matrix } & \multicolumn{3}{|c|}{ Factor } \\
\cline { 2 - 4 } Cronbach Alpha & $E I_{I}$ & $E I_{A}$ & $E I_{T}$ \\
\hline Indicators/Loadings & $\mathbf{0 . 9 6 5}$ & $\mathbf{0 . 9 5 1}$ & $\mathbf{0 . 8 7 9}$ \\
\hline$I_{7}$ & 0.973 & & \\
$I_{5}$ & 0.970 & & \\
$I_{4}$ & 0.911 & & \\
$I_{3}$ & 0.887 & & \\
$I_{6}$ & 0.858 & & \\
$I_{2}$ & 0.826 & & \\
\hline$A_{5}$ & & 0.958 & \\
$A_{4}$ & & 0.893 & \\
$A_{7}$ & & 0.879 & \\
$A_{6}$ & & 0.863 & \\
$A_{3}$ & & 0.795 & \\
\hline$T_{5}$ & & & 0.826 \\
$T_{2}$ & & & 0.820 \\
$T_{6}$ & & & \\
\hline
\end{tabular}

AUTHORS

A. Darja Topolšek, Phd, is the Associated Professor at the Faculty of Logistics, University of Maribor, Celje, Slovenia (e-mail: darja.topolsek@um.si).

B. Dejan Dragan, Phd, is the Assistant Professor at the Faculty of Logistics, University of Maribor, Celje, Slovenia (e-mail: dejan.dragan@um.si). 